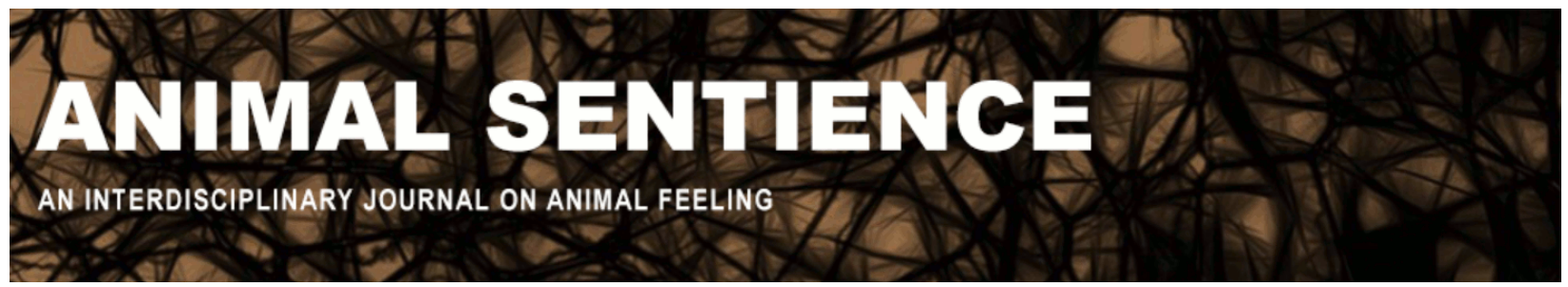

Gullone, Eleonora (2016) To minimize animal suffering, broaden the definition of animal cruelty. Animal Sentience 6(7)

DOI: $10.51291 / 2377-7478.1100$

Date of submission: 2016-03-08

Date of acceptance: 2016-03-23

(c)

This article has appeared in the journal Animal

Sentience, a peer-reviewed journal on animal

cognition and feeling. It has been made open access,

free for all, by WellBeing International and deposited

in the WBI Studies Repository. For more information,

please contact

wbisr-info@wellbeingintl.org.

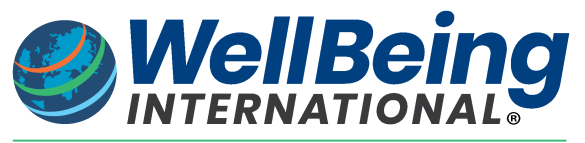

SOLUTIONS FOR PEOPLE, ANIMALS AND ENVIRONMENT 


\title{
To minimize animal suffering, broaden the definition of animal cruelty
}

Commentary on Lachance on Breaking Silence

\author{
Eleonora Gullone \\ Centre for Developmental Psychiatry and Psychology \\ Monash University, Australia
}

\begin{abstract}
Mandatory veterinary reporting of suspected abuse might discourage caregivers from seeking treatment for their injured animals. Animal abusers are more likely to be brought to justice by raising community awareness about the link between animal cruelty and human violence and its implications for the wellbeing of both humans and animals. Commonly accepted definitions of animal cruelty focus only on cruelty that is socially unacceptable, excluding an enormous amount of unnecessary animal suffering caused by humans. Only by broadening the definition of animal cruelty can we bring about the cultural change necessary to minimize this animal suffering.
\end{abstract}

Eleonora Gullone, Affiliate Associate Professor, Centre for Developmental Psychiatry and Psychology at Monash University, Australia, is the author of Animal Cruelty, Antisocial Behaviour, and Aggression: More Than a Link. https://www.researchgate.net/profil e/Eleonora Gullone

Animal abuse and cruelty affect billions of animals globally. Unfortunately, the vast majority of suffering inflicted upon animals, although completely unnecessary for human survival, is fully legal and socially acceptable (Agnew, 1998; Flynn, 2012). It includes the miserable conditions and deaths endured by animals on factory farms; the painful procedures inflicted upon animals in scientific experiments; and the suffering and deaths of thousands of animals every year who are involved in activities that humans consider recreational, including circuses, rodeos, bull fighting, dog and horse racing, hunting and fishing. The animal cruelty that has been classified as socially unacceptable and illegal occurs against this vast backdrop of cruelty that is legal and fully endorsed by respected institutions and democratically elected governments.

It is against this backdrop that professionals, including veterinarians, are expected to make ethical and moral decisions about reporting what they consider to be unacceptable behavior: Cruelty to animals is defined as behavior that causes unnecessary pain, suffering, distress or death (Ascione, 1999). The cruelty can be physical or psychological and it must be demonstrably deliberate (Brown, 1988; Dadds, Turner, \& McAloon, 2002).

The research findings on socially unsanctioned cruelty to animals are consistent with the broader literature on antisocial behaviour: As in all antisocial behavior, including family violence, it is males who are more likely to be cruel. This is true of children (e.g., Baldry, 2005), adolescents (Thompson \& Gullone, 2006), and adults (Gullone \& Clarke, 2008). For 
example, in an investigation of all animal cruelty cases prosecuted in Massachusetts between 1975 and 1996, Arluke and Luke (1997) found that approximately 97\% of the perpetrators were male. Gullone and Clarke (2008) analyzed all recorded offences in Victoria, Australia, from 1994 to 2001. When the data were broken down by age and sex, offenders were characteristically male across crime categories including animal cruelty. Males were overrepresented in all age categories but especially between age 18 and 35 .

Research on the link between family violence and animal cruelty has found that between $11.8 \%$ and $39.4 \%$ of women report that their perpetrators threatened to hurt or kill their companion animals. Between 25.6\% (Flynn, 2000) and 79.3\% (Quinslick, 1999) of women have reported that their perpetrators actually hurt or killed their companion animal(s). Many of the studies on animal cruelty in abusive families have also reported that between $18 \%$ (Ascione, 1998) and 48\% (Carlisle-Frank, Frank, \& Nielson, 2004) of women have delayed leaving their violent situations out of fear that their companion animal(s) would be harmed or killed if they were to leave. (See Gullone, 2012b, for a detailed review of the relationship between family violence and animal abuse.)

This research has also shown that children who have witnessed the violence - either humanor animal-directed - are themselves likely to engage in abusive behaviors (e.g., Baldry, 2003). Almost all participants who have reported having engaged in an act of animal cruelty also reported having been previously exposed to domestic and animal violence (Baldry, 2003).

In sum, the research on animal cruelty classified as socially unacceptable shows that the perpetrator is most likely to be male, aged between 18 and 35, and likely to be engaging in other criminal behaviors, including family violence. Factors leading to violence to animals reported by Kellert and Felthous (1985) include:

(i) attempts to control an animal (e.g., hitting a dog to stop it from barking),

(ii) retaliation against an animal (e.g., use of extreme punishment for a perceived transgression on the part of the animal such as throwing a cat against a wall for vomiting in the house),

(iii) acting out of prejudice against a particular species or breed,

(iv) expression of vicarious aggression through an animal (e.g., organising dog fights),

(v) enhancing one's own aggression (e.g., using animals for target practice or to impress others),

(vi) shocking people for amusement (cruelty that is very overt and observed by others),

(vii) retaliation or revenge against another person (e.g., killing or maiming the companion animal of a disliked neighbour),

(viii) displacement of aggression from a person to an animal, and

(ix) nonspecific sadism such as the desire to inflict suffering, injury or death in the absence of any particular hostile feelings toward an animal.

Factors vii and viii, especially control or retaliation, are the ones most likely to be relevant to the family violence situation. Many of the aggressive participants in Kellert and Felthous's (1985) study reported having been physically abused as children. Participants' self-reports were suggestive of displaced aggression, typically involving authority figures whom they reported hating or fearing so much that it prevented them from expressing their aggression 
directly. Their cruelty toward animals reportedly served as a displaced expression of the violence they had experienced.

The research on socially unacceptable animal abuse and cruelty suggests that an animal is most likely to be taken to a veterinarian for treatment by a caregiver following abuse by a stranger, a partner, or even the caregiver's own child (who might possibly also have been a victim of abuse). An animal abused because of factors $\mathrm{i}$ or ii may also be taken to a veterinarian for treatment by the abuser, perhaps out of remorse for having lost control and severely hurt an animal. It is unlikely that someone who has abused an animal because of the other factors, or as a means to some other end, would have any interest in seeking veterinary care.

Thus, if veterinarians are required to report abuse, will animals benefit? Given what we know about the factors leading to animal cruelty, this would depend very much on the specific situation. A perpetrator motivated to abuse an animal specifically to cause suffering and/or death is unlikely to seek medical attention for the victim. If the perpetrator is a partner or spouse of the animal's caregiver, will mandatory reporting place the caregiver and the animal at risk of further abuse? If the animal's caregiver is the parent of a child, will mandatory reporting benefit either the animal or the child?

The Australian Veterinary Association (AVA) has adopted the policy that veterinarians should report suspected animal abuse to the relevant authorities but they should not be required to do so by law. The AVA notes that the concern about mandatory reporting is that it could discourage owners from seeking treatment for their injured animals (Australian Veterinary Association, 2016).

Ultimately, the goal is to minimize animal suffering and to bring abusers to justice. This goal is most likely to be achieved by raising community awareness of the implications of animal cruelty crimes for the wellbeing of society, including both humans and animals. Education is needed about the link between animal cruelty and human violence (Gullone, 2012a). This is a link which has recently been acknowledged formally by crime fighting institutions including the United States Federal Bureau of Investigation, which is required as of 2016 to track socially unacceptable animal cruelty along with other crimes including rape and assault (see Crimes against Society, 2016). This initiative will undoubtedly be helpful in changing cultural attitudes so that animal cruelty comes to be regarded as the antisocial and aggressive behavior that it is.

This initiative, however, focuses only on animal cruelty that is deemed to be socially unacceptable. Less well known is the research that also shows a link between socially acceptable, legally sanctioned animal cruelty and human aggression. We need to ask ourselves, for example, why there are significantly higher levels of crime and violence in towns where there are slaughterhouses (Fitzgerald, Kalof, \& Dietz, 2009)? Ultimately, the cultural change needed to redress the enormity of suffering inflicted on animals by humans can only come about once we see fit to reject a long-standing but arbitrary, artificial, anthropocentric and amoral distinction: the distinction between that small subset of humaninflicted animal suffering that we currently deem to be socially unacceptable and that vast superset of human-inflicted animal suffering that we currently accept without question. It is 
self-evident that treating the vast majority of cruelty to animals as socially acceptable heightens both our tolerance for causing suffering to other species and our likelihood of causing it. But the evidence of the link between violence against animals and violence against humans goes on to suggest that our heightened tolerance for causing suffering does not stop at the (arbitrary) boundary between species, nor does our likelihood of causing it. If we were instead to broaden our definition of animal cruelty, might this not enlarge our sphere of compassion toward all sentient species, including our own?

\section{References}

Agnew, R. (1998). The causes of animal abuse: A social-psychological analysis. Theoretical Criminology, 2, 177-209.

Arluke, A., \& Luke, C. (1997). Physical cruelty toward animals in Massachusetts, 1975-1996. Society \& Animals, 5, 195-204.

Ascione, F. R. (1998). Battered women's reports of their partners' and their children's cruelty to animals. Journal of Emotional Abuse, 1, 119-133.

Ascione, F. R. (1999). The abuse of animals and human interpersonal violence: Making the connection. In F. Ascione \& P. Arkow (Eds.), Child abuse, domestic violence, and animal abuse: Linking the circles of compassion for prevention and intervention (pp. 50-61). West Lafayette, Indiana: Purdue University Press.

Australian Veterinary Association. (2016). From the president: Animal cruelty and reporting. http://www.ava.com.au/13383. Downloaded March 1, 2016.

Baldry, A. C. (2003). Animal abuse and exposure to interparenteral violence in Italian youth. Journal of Interpersonal Violence, 18(3), 258-281.

Baldry, A. C. (2005). Animal abuse among preadolescents directly and indirectly victimized at school and at home. Criminal Behaviour and Mental Health, 15, 97-110.

Brown, L. (1988).Cruelty to animals: The moral debt. London: Macmillan.

Carlisle-Frank, P., Frank, J. M., \& Nielsen, L. (2004). Selective battering of the family pet. Anthrozoos, 17, 26-42.

Crimes against Society. (2016). https://www.facebook.com/HuffingtonPost/videos/10153676155061130/. Downloaded March 1, 2016.

Dadds, M. R., Turner, C. M., \& McAloon, J. (2002). Developmental links between cruelty to animals and human violence. Australian \& New Zealand Journal of Counselling, 35, 363382.

Fitzgerald, A. J., Kalof, L., \& Dietz, T. (2009). Slaughterhouses and increased crime rates: An empirical analysis of the spillover from "The Jungle" into the surrounding community. Organization \& Environment, 22, 158-184.

Flynn, C. P. (2000). Why family professionals can no longer ignore violence toward animals. Family Relations: Interdisciplinary Journal of Applied Family Studies, 49, 87-95.

Flynn, C. P. (2012). Understanding animal abuse: A sociological analysis. New York: Lantern Books.

Gullone, E. (2012a). Animal cruelty, antisocial behaviour, and aggression: More than a Link. United Kingdom: Palgrave-MacMillan.

Gullone, E. (2012b). Animal cruelty and family violence. In C. L. Reyes \& M. P. Brewster (Eds.), Animal cruelty and the Criminal Justice System. Carolina Academic Press. 
Gullone, E., \& Clarke, J. (2008). Human-Animal Interactions: The Australian Perspective. In F. Ascione (Ed.), The International Handbook of Theory and Research on Animal Abuse and Cruelty (pp. 305-335). West Lafayette, Indiana: Purdue University Press.

Kellert, S. R., \& Felthous, A. R. (1985). Childhood cruelty toward animals among criminals and noncriminals. Human Relations, 38(12), 1113-1129.

Lachance, M. (2016). Breaking the silence: The veterinarian's duty to report. Animal Sentience 2016.006: 1-16.

Quinslick, J. A. (1999). Animal abuse and family violence. In F. R. Ascione \& P. Arkow (Eds.), Child abuse, domestic violence, and animal abuse: Linking the circles of compassion for prevention and intervention. (pp. 168-175). Indiana: Purdue University Press.

Thompson, K. L., \& Gullone, E. (2006). An investigation into the association between the witnessing of animal abuse and adolescents' behavior toward animals. Society \& Animals, $14,223-243$. 